\title{
A FUNÇÃO HERMENÊUTICA DO DIREITO FUNDAMENTAL À BOA GOVERNANÇA
}

\author{
THE HERMENEUTIC FUNCTION OF FUNDAMENTAL LAW \\ TO GOOD GOVERNANCE
}

Claudio Carneiro B. P. Coelho ${ }^{1}$

Marcelo Quentin ${ }^{2}$

\begin{abstract}
Resumo: O presente artigo busca apresentar o conteúdo hermenêutico do Direito Fundamental à Boa Governança. Para tanto, inicialmente aborda a ideia de governança, partindo da influência que esse conceito sofreu do seu antecessor, isto é, de governabilidade. Fixado o conceito, desenvolve-se uma investigação sobre a formação do conteúdo jurídico do direito à boa governança, como cláusula geral a introduzir no sistema de controle de políticas públicas, aspectos finalísticos, procedimentais e econômicos. Mais à frente destaca o conteúdo do direito à boa governança com status de direito fundamental, calcado na Carta de Direitos Fundamentais da Europa (Carte de Nice), no caso específico dos países europeus do bloco, e ainda, como direito fundamental implícito, no caso brasileiro, tendo como escopo os seu aspecto democrático e republicano. Por fim, revela-se o conteúdo hermenêutico do direito fundamental à boa governança, propondo-se a identificação de que tal função hermenêutica, implementada pelo Poder Judiciário, deve estar centrada dentro de um binômio limitativo. De um lado, o controle proativo finalístico e procedimental por parte do Poder Judiciário e, de outro, como ponto limitador desta atuação, a autocontenção judicial em matérias de puro mérito administrativo.
\end{abstract}

Palavras-chave: Direito Fundamental. Boa Governança. Hermenêutica Jurídica.

\begin{abstract}
This article aims to present the hermeneutical content of the Fundamental Right to Good Governance. Therefore, it initially addresses the idea of governance, starting from the influence that this concept suffered from the governability. Once the concept has been established, an investigation is carried out on the formation of the legal content of the right to good governance, as a general clause to be introduced in the public policy control system, with final, procedural and economic aspects. Further on, it highlights the content of the right to good governance with the status of a fundamental right, based on the Charter of Fundamental Rights of Europe (Nice Charter), in the specific case of the European countries of the bloc, and also, as an implicit fundamental right, in the case Brazilian, having as its scope the democratic and republican aspects. Finally, the hermeneutic content of the fundamental right to good governance is revealed, proposing the identification that such hermeneutical function, implemented by the Judiciary, must be centered within a limiting binomial. On the one hand, the

\footnotetext{
${ }^{1}$ Advogado. Pós-doutor pela Universidade Nova de Lisboa. Doutor em Direito Público. Pós-doutorando pela Universidade de Salamanca (Espanha). Coordenador do PPG em Direito do Centro Universitário Guanambi/BA. Professor Visitante do Curso de Mestrado da UAL (Portugal). Professor convidado da FGV (Brasil) e da EMERJ. Vice-presidente da Ethical \& Compliance International Institute. Conselheiro da OAB/RJ. Presidente da Comissão de Direito à Educação da OAB/RJ. Coordenador do Centro Baiano de Investigação sobre Direito, Educação e Políticas Públicas da UniFG. Contato: professorclaudiocarneiro@gmail.com

${ }^{22}$ Juiz de Direito e juiz eleitoral no Estado do Paraná. Graduado em Direito pela Universidade Federal do Paraná (UFPR). Mestrando em Ciências Jurídicas pela Universidade Autônoma de Lisboa (UAL- Portugal). Formador de magistrados credenciado pela Escola Nacional de Formação e Aperfeiçoamento de Magistrados (ENFAM). Membro eleito do Comitê Gestor de Gestão de Pessoas do TJPR. Atuou como Juiz Auxiliar da presidência do TRE/PR na coordenação do processo da biometria. Coordenador e professor da Escola da Magistratura do Estado do Paraná (EMAP) no curso de pós-graduação e nos preparatórios para concursos públicos. Consultor científico da Editora Appris. Contato: maq@tjpr.jus.br
} 
proactive, finalistic and procedural control by the Judiciary Branch and, on the other, as a limiting point of this action, the judicial self-restraint in matters of pure administrative merit.

Keywords: Fundamental Law. Good Governance. Legal Hermeneutics.

\section{Introdução}

O presente artigo parte de uma análise do conceito e do conteúdo hermenêutico da boa governança, sobretudo dentro do contexto do estudo dos direitos fundamentais, adentrando-se brevemente nas questões sobre o status da boa governança dentro do arcabouço de direitos fundamentais existentes.

Uma vez reconhecida a boa governança como inserida no conjunto dos direitos fundamentais, pretende-se compreender suas funções dentro do sistema constitucional, enfatizando-se o seu aspecto hermenêutico em face de sistemas que adotam o "judicial review" como é o caso de Portugal e, também, do Brasil.

Sabe-se que a consecução de direitos fundamentais, sobretudo os de segunda dimensão ou geração (para alguns), consagrados como direitos de liberdade, é matéria que depende de muito mais do que meras declarações de cunho programático para se efetivarem e se concretizarem. Via de regra, a consecução de direitos fundamentais de segunda dimensão, como os direitos sociais, por exemplo, demanda uma atuação positiva do Estado. Isto é, para concretizar direitos sociais o Estado precisa dispender energia, precisa atuar positivamente, precisa, ao cabo, de recursos.

Há quem diga, inclusive, que a distinção entre direitos negativos e positivos, no sentido em que os primeiros demandariam um "non facere" do Estado em contrariedade ao "facere" demandado pelos direitos positivos, de fato não faz sentido, já que todos os direitos importam efetivamente em um custo ao Erário $^{3}$.

Não se pode deixar de lado que o fato de que os direitos sociais ou a sua concretização representam um custo financeiro para o Estado. Nos casos dos direitos sociais, aliás, como direitos positivos que são, dentro da clássica diferenciação e abstraindo das críticas, é ainda mais evidente e induvidosa a conclusão sobre o custo dos direitos.

Assim sendo, por mais que se tenha como certo o mister dos Estados em dar azo à concretização de direitos fundamentais, sobretudo Estados que adotam para si a função e o dever de implementar avanços sociais, com fito no bem-estar das pessoas; é preciso se ter em mente que todo direito social tem, como dito, o seu respectivo custo.

\footnotetext{
${ }^{3}$ HOLMES, Stephen; SUSTEIN, Cass R. O Custo dos Direitos: Por que a Liberdade Depende de Impostos. Tradução de Marcelo Brandão Cipolla. São Paulo: Editora WMF Martins Fontes, 2019. p. 27.
} 
Mais do que isso, que a análise econômica da consecução desses direitos não significa uma redução ou uma "capitis diminutio" dos direitos sociais, antes os eleva e os garante para que não virem letra morta ou meras declarações em uma mera "folha de papel” na consagrada expressão de Ferdinand Lassale ${ }^{4}$.

Nesse sentido é que se coloca a boa governança como um direito fundamental, na medida em que não há direitos sem recursos e que a consecução dos direitos depende da existência de um orçamento que lhes faça frente. Se os direitos dependem de orçamento, a boa governança é um dos instrumentos capazes de dar eficiência econômica ao Estado, funcionando assim como um vetor de garantia para que o Estado seja capaz de fazer frente aos anseios de prestador positivo de direitos sociais.

É importante a discussão, portanto, no sentido de analisarem-se os direitos sociais sob um duplo olhar, conforme afirma Cláudio Carneiro 5 , "de um lado os direitos fundamentais sociais enquanto força (previsão) normativa de âmbito constitucional e, de outro, a obtenção de recursos que sejam suficientes para realização das despesas públicas”.

\section{Da governabilidade à boa governança}

Governança é conceito que se forma a partir de outro vocábulo bastante conhecido na década de 70, que é a governabilidade. Pode a governabilidade ser definida em pelo menos quatro vertentes de que trataremos rapidamente.

$\mathrm{Na}$ primeira, a ideia de governabilidade é identificada como "a distância entre as demandas sociais a as habilidades das instituições públicas em satisfazê-las”, o que envolve, portanto, uma dimensão político-institucional ${ }^{6}$. Governabilidade seria, portanto, a habilidade de, por meio de instituições públicas, fazer frente a demandas sociais.

Uma segunda vertente do conceito de governabilidade é aplicada à compreensão dos processos de transição democrática, notadamente nos países da América Latina, em que se reconhece a governabilidade como a "capacidade das instituições públicas de fazer frente aos desafios com que se defrontem, sobretudo no sentido de evitar a autocracia e expandir os direitos e oportunidades das pessoas"7. Nessa vertente, é perceptível o caráter mais

\footnotetext{
${ }^{4}$ LASSALE, Ferdinand. O que é uma Constituição. Rio de Janeiro: Larmert, 1960.

${ }^{5}$ CARNEIRO, Cláudio. AInda é Possível Falar em Direito Sociais? In. Os Desafios do Direito no Século XXI: Violência, Criminalização, Consenso, Tutela Digital e Laboral. Coord. Manuel Monteiro Guedes Valente. Coimbra: Almedina. 2019. p. 154.

${ }^{6}$ Cf. REIS, Fábio Wanderley. Governabilidade, instituições e partidos. Novos Estudos - CEBRAP, $\mathrm{n}^{\circ} 41$, março/1995. p. 42.

${ }^{7}$ Cf. PRATS, Joan Oriol. El concepto y el análises de la gobernabilidad. Revista Instituciones y desarrollo. Institut Internacional de Governabilitat de Catalunya, No 14-15. 2003. p. 241.
} 
intervencionista no sentido de implementar direitos sociais de igualdade, por meio de instituições públicas.

Quanto à terceira vertente, foi utilizada pelo Banco Mundial e outros organismos internacionais, colocando-se a governabilidade como "o exercício da autoridade através de tradições e instituições para o bem comum e assim compreendendo: o processo de selecionar, monitorar e substituir os governos; a capacidade de formular e implementar políticas responsáveis e prestar serviços públicos; e o respeito dos cidadãos e do Estado às instituições que governam as interações econômicas e sociais entre eles" ${ }^{\prime 8}$. Nessa vertente, portanto, tentase fechar o conceito, tornando-se-o mais completo, acrescendo os aspectos relacionados ao controle do governo, na medida em que se identifica a governabilidade dentro do próprio processo de formação deste, em sua fiscalização e até mesmo em sua substituição. Passa também o conceito pela implementação de serviços públicos e de políticas públicas calcadas na melhoria social.

Por fim, a quarta vertente da governabilidade está associada ao processo de consolidação da União Europeia, em que "a governabilidade descreve a estrutura de tomada de decisões em redes múltiplas envolvendo atores governamentais e não governamentais a um só tempo". Nessa última, o conceito agrega as ideias de complexos múltiplos de tomada de decisões e o envolvimento de atores não governamentais para além das instituições públicas.

O entendimento do conceito de governabilidade que, como veremos, não destoa tanto assim da ideia de governança, deve ser, portanto, compreendido consideradas as quatro vertentes acima expostas.

De se anotar, contudo, que o termo governabilidade passou por um período em que chegou a ser considerado um vocábulo de carga semântica absolutamente negativa, vindo à época a ser associado a uma espécie de retrocesso democrático, na medida em que justificaria a relativização de avanços sociais em face de uma suposta sobrecarga do sistema e, também, por conta de um crescimento cada vez maior das demandas sociais em contrapartida às dificuldades do Estado em fazer frente a estas. Como se a ideia de governabilidade fosse uma negação da afirmação de direitos sociais, o que de fato não é.

Essa carga negativa, contudo, acaba por gerar a necessidade de evoluir o conceito, passando então ao enfoque menos voltado aos atributos do Estado ou do Governo como

8 KAUFFMANN, Daniel. Replanteando Gobernabilidad. Las Lecciones Empíricas Desafían a los Convencionalismos. Instituto del Banco Mundial. 2010. disponível em:

$<$ http://siteresources.worldbank.org/INTWBIGOVANTCORINSPA/Resources/reth ink_gov-e.pdf>, acesso em dezembro de 2020. 
estrutura, e voltando-se mais às claras deficiências do governo como prática dinâmica. Assim dá-se início à ideia e do conceito de governança9 ${ }^{9}$.

Após trilhar o caminho desde o conceito de governabilidade, chegando-se especificamente ao conceito de governança, este passa a ser traduzido em 1992 pelo Banco Mundial como um tipo de poder exercido na administração de recursos.

Nesse viés, o conceito abraça três diferentes aspectos: Primeiro quanto à forma como se reveste o regime político do país; segundo, quanto ao processo por meio do qual a autoridade é exercida na gestão dos recursos econômicos e sociais do dado país, voltado ao seu desenvolvimento; por fim, no que concerne à capacidade dos governos de conceber, formular e implementar políticas de modo a se desincumbir de suas funções ${ }^{10}$.

Claramente, o conceito de governança abarcado pelo Banco Mundial neste momento é de uma visão central do Estado, o qual assume as funções de integrador da diversidade, orientador das dinâmicas sociais e decompositor da complexidade, na busca de uma direção da sociedade, regida por um princípio de coerência ${ }^{11}$.

Mais à frente, especificamente no ano de 2007, o conceito se renova alcançando o que se chamou de um verdadeiro refinamento quanto ao sentido original. Refinamento este dado pelo mesmo Banco Mundial, por meio de um grupo temático destinado à governança e ao combate à corrupção.

O conceito foi enunciado da seguinte maneira: "Governança se refere à maneira através da qual os agentes e instituições públicas adquirem e exercem sua autoridade para o provimento de bens e serviços públicos incluindo a oferta de serviços essenciais, infraestrutura e um ambiente favorável ao investimento",12 13.

Acrescem-se, portanto, ao que havia sido enunciado em 1992, dois elementos, quais sejam: a origem da autoridade, dando-lhe legitimidade, e a concretização das tarefas, isto é, o resultado buscado.

Vale mencionar ainda que as Nações Unidas também traçaram um conceito de governança, identificando-a com o processo de tomada de decisões e a implementação destas

\footnotetext{
${ }^{9}$ VALLE, Vanice Regina Lírio do. Direito Fundamental à boa administração e governança: democratizando a funcao administrativa. Tese de Pós-doutorado apresentado na Fundação Getúlio Vargas. Rio de Janeiro. 2010. p. 81-82. Disponível em: <http://bibliotecadigital.fgv.br/dspace/handle/10438/6977> acesso em dezembro de 2020.

${ }^{10}$ Ibidem. p. 83.

${ }^{11}$ ROCHA, J. A. Oliveira. Gestão pública e modernização administrativa. INA Editora, 2014. p. 186.

12 THE WORLD BANK. Strengthening World Bank Group engagement on governance And anticorruption, 2007, p. 67. Disponível em:

<http://www.wds.worldbank.org/external/default/WDSContentServer/WDSP/IB/1994/05/01/000009265_39707 16142854/Rendered/PDF/multiopage.pdf >, acesso em dezembro de 2020.

${ }^{13}$ Conferir também: VALLE, Vanice Regina Lírio do. Op. cit. p. 84-85.
} 
decisões. Especificamente quanto ao processo, é de se frisar que se trata de um processo que se pretende participativo e orientado pelo consenso, responsável, transparente, efetivo, eficiente, inclusivo e orientado pelo Direito ${ }^{14}$.

$\mathrm{Na}$ União Europeia, o conceito de governança veio expresso no que ficou conhecido como "Um Livro Branco"15, em 2001, no seguinte sentido: "governança designa as normas, processos e comportamentos que influem no exercício dos poderes a nível europeu, especialmente desde o ponto de vista da abertura, participação, responsabilização, eficácia e coerência" ${ }^{\prime \prime}$.

Constata-se, portanto, que neste momento exsurge uma diferença sensível na compreensão do conceito de governança, sobretudo em comparação com o conceito de governabilidade, no que tange à ênfase não mais na dimensão institucional como estruturante da arquitetura do poder, mas sim em sua faceta dinâmica, na prática diária das funções do Estado. A governança, para além da governabilidade é, portanto, compreendida como um processo, um agir dinâmico.

O modo de operar as políticas governamentais é o principal enfoque agora e vai variar desde a formação do processo político-decisório dos governos até os mecanismos democráticos de avaliação, levando-se em conta a cooperação entre todos que possam concorrer para a superação das insuficiências do Estado, de modo, assim, a democratizar a sua atuação cada vez mais.

Claudio Carneiro ${ }^{17}$, em síntese, indica que:

é possível afirmar que, atualmente, o Estado Social (e os direitos sociais) não se viabiliza sem que haja o desenvolvimento econômico do Estado (estabilidade econômica e financeira) e, também, uma boa gestão pública (Boa Governança) que assegure a concretização (efetividade) dos direitos sociais para os seus reais destinatários, isto é, a sociedade.

Significa dizer que, cumpre ao Estado dar solução aos problemas coletivos, mas estes demandam também a participação de outros atores sociais ${ }^{18}$.

\footnotetext{
${ }^{14}$ VALLE, Vanice Regina Lírio do. op, cit. p. 85.

15 COMISSÃO DAS COMUIDADES EUROPEIAS. Governança Europeia: Um Livro Branco. 2001. Disponível em: < http://www.laicidade.org/wp-content/uploads/2006/09/ue-governanca-2001.pdf. > Acesso em dezembro de 2020.

${ }^{16}$ VALLE, Vanice Regina Lírio do. op, cit. p. 86.

17 COELHO, Claudio Carneiro B. P. Teoria do Pêndulo Econômico-hermenêutico. Uma releitura da relação entre Estado, Direito e sociedade em tempo de (pós) crise. Rio de Janeiro: University Institute. 2021. p. 110;

${ }^{18}$ Ibidem. p. 87.
} 


\section{A construção jurídica do direito à boa governança e à boa administração}

Boa governança é associada à ideia, portanto, de boa administração, de bom trato da coisa pública, de boa consecução dos interesses públicos. É afinal um meio de se agregarem diversos princípios constitucionais e sobretudo os princípios da Administração Pública, donde se retira primeiramente o seu conteúdo jurídico. Além disso, a boa governança está intimamente ligada ao debate econômico, político e social e não apenas à boa prestação do serviço público ${ }^{19}$.

De início, poder-se-ia até mesmo tecer alguma crítica ao aspecto fluido que o termo "boa governança" poderia representar, gerando-se uma certa incerteza na sua aplicabilidade jurídica devido à sua fluidez de significado; mas de fato essa fluidez não é o que deve impedir o conceito de ser bem explorado e nem evitar que surta, ao cabo, os efeitos próprios que o Direito lhe determina; aliás, exatamente como ocorre com outras cláusulas gerais ou outros conceitos jurídicos indeterminados do Direito, o que é característica recente inclusive dos enunciados de status constitucional ${ }^{20}$.

Conceitos como o de boa-fé, por exemplo, apesar de parecerem causa de problema pela sua fluidez e pluralidade de significados, em verdade são importantes para a consagração dos direitos, desde que se lhes dê a interpretação apropriada e desde que se lhes reconheça uma densidade mínima, sem o que não poderiam sequer ser considerados direitos se não meras exortações.

Perceptível, portanto, a importância da hermenêutica para casos de conceitos jurídicos indeterminados ou cláusulas gerais, o que não é diferente com a boa governança, em cuja análise caberá ao intérprete avaliar de forma concreta e até mesmo empírica o que é ou não boa governança dentro dos casos concretos, identificando-se, a contrário senso, caso a caso, os casos de má governança.

Vale dizer ainda, que a inserção no sistema de conceitos jurídicos plurissignificativos serve deliberadamente para se gerar uma margem de discricionariedade ao administrador público, que de modo algum é nefasta e sim corresponde a uma necessária liberdade na consecução das funções administrativas; mas que, no entanto, evidentemente, deve se

\footnotetext{
${ }^{19}$ Cf. CARVAlho, Valter Alves. O Direito à Boa Administração Pública: Uma Análise no Contexto dos Direitos de Cidadania no Brasil. Dissertação de Mestrado. Universidade Federal Fluminense. 2013. p. 63. Disponívelem:<http://ppgdc.sites.uff.br/wp-content/uploads/sites/34/2017/06/DISSERTA\%C3\%87\%C3\%83O__Valter_Alves_Carvalho.pdf $>$ acesso em dezembro de 2020.

${ }^{20}$ Cf. BARROSO, Luís Roberto. Curso de Direito Constitucional Contemporâneo: os conceitos fundamentais e

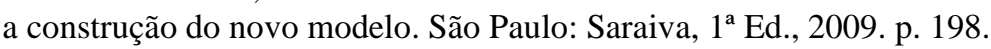


submeter a controle (seja interno ou externo), não do mérito dos atos, mas, em suma, da sua legitimidade ${ }^{21}$.

Esse traço, aliás, se amolda a sistemas nos quais se adota o "judicial review" como o mais eficaz controle externo da atividade administrativa. E ademais, como argumenta Herbert Hart, é sabido que um certo grau de imprecisão é algo inerente à própria linguagem do Direito $^{22}$, não configurando nenhuma novidade o aspecto plurissignificativo do direito fundamental à boa governança.

A boa governança deve superar os aspectos da burocracia, não se limitando apenas em princípios como legalidade, impessoalidade, moralidade, entre outros, para que se tenha em foco uma administração mais voltada ao ponto de vista dos destinatários, à eficiência e eficácia. Assim sendo, "a bondade no caso é uma bondade referenciada em todo o caso a respeito dos interesses e da posição concreta dos cidadãos interessados e não somente nos interesses da Administração"23.

Nesse quadro, é importante ao direito de boa governança e à boa administração a ancoragem na teoria dos direitos fundamentais, como se pretende neste trabalho, ao que se eleva o princípio a um caráter determinante a ponto de, caso seja concretizado, terminar por fomentar a própria proteção aos mesmos direitos fundamentais, num verdadeiro movimento de retroalimentação ${ }^{24}$. Assim, concretizar a boa governança como direito fundamental é ao cabo concretizar os próprios direitos fundamentais.

\section{4. $O$ direito fundamental à boa governança e à boa administração}

O processo de consagração da boa governança ou boa administração pública como direito fundamental se inicia no direito comunitário europeu. Primeiramente como uma expressão de um princípio geral do direito e depois, com grande influência do Provedor de Justiça Europeu (European Ombudsman), justamente por conta da sua função de apurar casos de má administração, passa-se à previsão expressa na Carta de Nice ou Carta de Direitos Fundamentais da União Europeia, aprovada em $2000^{25}$.

\footnotetext{
${ }^{21}$ Cf. MELlo, Celso Antônio Bandeira de. Discricionariedade e controle jurisdicional. $2^{\mathrm{a}}$ ed. $8^{\mathrm{a}}$ tiragem. São Paulo: Malheiros, 2007. p. 19 e seguintes.

${ }^{22}$ Cf. HART, Herbert Lionel Adolphus. O conceito de direito. São Paulo: Martins Fontes, 2012.

23 SOUVIRÓN MORENILLA, José Maria. Sentido y alcance del derecho a una buena administración. In: RODRÍGUEZ, Carmen María Ávila. RODRÍGUEZ, Francisco Gutiérrez (Coord.). El derecho a una buena administración y la ética pública. Valencia: Tirant lo Blanch, 2011. p. 236.

${ }^{24}$ CARVALHO, Valter Alves. Op. cit. p. 66.

${ }^{25}$ Ibidem. p. 66 e seguintes.
} 
Percebe-se então que o caminho para se chegar à Carta de Nice passou por definições empíricas do que não seria uma boa administração (sendo, portanto, considerado má administração), por meio de influência do Ombudsman europeu. Atos como desrespeito a direitos fundamentais, omissões estatais, abusos de poder, negligência, procedimentos ilegais, deslealdade, disfunção e incompetência, atrasos, falta de informação ou recusa desta, etc., são classificados, não taxativamente, como casos de má administração e a partir daí começa-se, a contrário senso, a se definir o que seria o direito fundamental à boa administração.

Vale mencionar que também o Código Europeu de Boa Conduta Administrativa adveio por influência do Onbudsman, este aprovado em $2001^{26}$ e que teve também grande influência na definição do direito fundamental à boa governança, fazendo referência a princípios como proporcionalidade, não-discriminação, legalidade, vedação de abuso de poder, transparência, entre outros.

Importante frisar que o Código Europeu de Boa Conduta Administrativa não se trata de um documento normativo propriamente, estando mais relacionado a uma ideia de "soft law", eis que embora não normativo é instrumento criado por meio de um processo argumentativo interinstitucional, servindo assim de grande vetor hermenêutico do direito posto e, especificamente, a influenciar diretamente a aplicação do direito fundamental à boa administração; este que já vinha consagrado na Carta de Nice desde o ano 2000, mas que somente ganha status de Tratado, com imposição normativa e cogência aos países membros, em 2009, com o Tratado de Lisboa ${ }^{27}$.

$\mathrm{Na}$ Carta de Nice, então, com vigência desde 2009, se expressa no artigo 41 (também importantes os artigos 42 a 44) o Direito a uma boa administração ${ }^{28}$; importantíssimo

26 CÓDIGO EUROPEU DE BOA CONDUTA ADMINISTRATIVA. Provedor de Justiça Europeu. 2002. Disponível em: < https://www.ombudsman.europa.eu/pt/publication/pt/3510\#hl9 > acesso em dezembro de 2020.

${ }^{27}$ O Tratado de Lisboa foi assinado em 13/12/2007 e entrou em vigor em 01/12/2009. No seu artigo 6. ${ }^{\circ}$, n. 1 , é reconhecida a natureza de tratado à Carta de Direitos Fundamentais da União Europeia: " $A$ União reconhece os direitos, as liberdades e os princípios enunciados na Carta dos Direitos Fundamentais da União Europeia, de 7 de dezembro de 2000, com as adaptações que lhe foram introduzidas em 12 de Dezembro de 2007, em Estrasburgo, e que tem o mesmo valor jurídico que os Tratados." In. CARVALHO, Valter Alves. Op. cit. p. 70. 28 "Artigo 41. ${ }^{\circ}$ - Direito a uma boa administração: Todas as pessoas têm direito a que os seus assuntos sejam tratados pelas instituições, órgãos e organismos da União de forma imparcial, equitativa e num prazo razoável. 1. Este direito compreende, nomeadamente: $O$ direito de qualquer pessoa a ser ouvida antes de a seu respeito ser tomada qualquer medida individual que a afecte desfavoravelmente; $O$ direito de qualquer pessoa a ter acesso aos processos que se lhe refiram, no respeito pelos legítimos interesses da confidencialidade e do segredo profissional e comercial; A obrigação, por parte da administração, de fundamentar as suas decisões. Todas as pessoas têm direito à reparação, por parte da União, dos danos causados pelas suas instituições ou pelos seus agentes no exercício das respectivas funções, de acordo com os princípios gerais comuns às legislações dos Estados-Membros. Todas as pessoas têm a possibilidade de se dirigir às instituições da União numa das línguas dos Tratados, devendo obter uma resposta na mesma língua”. 
elemento, portanto, para a consagração da boa governança como direito fundamental na Europa.

Vale frisar que, embora de grande valia para a União Europeia e para o direito fundamental em si, mundialmente consagrado, algumas críticas às disposições da Carta de Nice fizeram com que se incentivasse a conformação deste princípio dentro dos próprios estados membros do bloco, internamente.

Tal incentivo culminou com uma recomendação pelo Comitê de Ministros de Estados Membros, em 2007, de que os países da UE promovessem a boa administração dentro do quadro de princípios do Estado de Direito e da Democracia, mediante o funcionamento de administrações públicas assecuratórias da eficácia, eficiência e economia, bem como a promoção da boa administração no interesse de todos, com adoção de normas específicas ${ }^{29}$. E assim devem proceder os países da União Europeia desde então.

Do conjunto da obra, portanto, não há dúvida de que, na Europa, o direito à boa governança é um direito fundamental e a Carta de Direitos Fundamentais da União Europeia (Carta de Nice) constitui elemento decisivo para esta constatação, pois dispõe, como visto, de forma expressa, sobre o seu status ${ }^{30}$.

Quanto ao Brasil, não há como fazer a remessa ao Tratado de Nice, a título de assunção do texto para consagração do direito fundamental à boa governança, por evidente, já que serve à União Europeia; o que, contudo, não afasta a possibilidade da influência do tratado no direito brasileiro à guisa de comparação e como importante instrumento de hermenêutica.

No Brasil, em verdade, o direito fundamental à boa governança há de ser considerado implícito no texto da Constituição, notadamente como desdobramento dos princípios constitucionais da Administração Pública consagrados sobretudo no artigo 37 da /Constituição de 1988.

Correta, portanto, sem sombra de dúvida, a conclusão de Claudio Carneiro no sentido de que:

A Boa Governança, atualmente, também deve ser tratada como verdadeiro direito fundamental, e não como mera recomendação ao administrador, seja ele público ou privado, pois o mau governo seja por escolhas indevidas por parte de seus gestores ou, simplesmente, por atos de corrupção ou suborno, acabam por comprometer direitos (no campo da eficácia) assegurados nas

\footnotetext{
${ }^{29}$ CARVALHO, Valter Alves. Op. cit. p. 71.

${ }^{30}$ Ver também: LIRA, Bruno de Oliveira. O Direito Fundamental à Boa Administração sob a ótica do Estado. 2011. Disponível em: < http://jus.com.br/artigos/18515/o-direito-fundamental-a-boa-administracao-sob-aotica-do-estado>. Acesso em dezembro de 2020.
} 
constituições e, com isso, andar na contramão da evolução do que tem sido chamado de (Neo) constitucionalismo ${ }^{31}$.

Mas de fato, a inexistência de uma disposição expressa, como há na Europa, para se agasalhar o direito fundamental à boa governança no Brasil contribui para que haja uma certa dificuldade de aceitação deste direito, muito em função do seu caráter procedimental (como vimos ao longo do trabalho), já que a sua efetivação depende da existência e da implementação de estruturas e organizações que lhe façam as vezes ${ }^{32}$.

No entanto, mesmo aqueles que enxergam essa dificuldade de aceitação, não afastam (e nem poderiam) a ideia de que, minimamente, o direito fundamental à boa governança pode ser enquadrado em um direito de prestação do Estado, ainda que implícito. Isso porque é bastante claro que o reconhecimento do direito à boa governança decorre da percepção de que o Estado deve garantir o interesse público e deve atender às expectativas concretas dos cidadãos, algo que não se concretizará jamais sem a garantia de uma boa administração, no exato sentido da ideia de boa governança como direito fundamental.

Importante considerar que, uma vez que o Estado toma para si a função de formular o Direito e manter a ordem jurídica; e ainda, para além disso, assume o mister de dar azo aos interesses gerais atinentes à sociedade, é claro que, enquanto Estado-Administração, assume também implicitamente os deveres e os ônus de executar todas as atribuições desse mister no mais alto grau possível de qualidade e excelência, para que assim dê consecução a tudo que lhe é encargo de modo eficiente.

Nesses termos, arremata MOREIRA NETO ${ }^{33}$ :

A boa administração, portanto, não é uma finalidade disponível, que possa ser eventualmente atingida pelo Poder Público: é um dever constitucional de quem quer que se ponha a gerir, de livre e espontânea vontade, os interesses públicos. Por isso mesmo, em contrapartida, a boa administração corresponde a um direito cívico do administrado - implícito da cidadania.

É dizer, a boa administração além de calcada no processo de consecução dos interesses públicos é um direito próprio do cidadão, inerente à sua condição de cidadão; direito este com envergadura constitucional, escoimada nos princípios da Administração Pública, em observância aos quais o processo de concretização dos interesses sociais há de ser mais e mais eficiente, sob pena de que os governantes acabem por desatender o escopo geral da

\footnotetext{
${ }^{31}$ CARNEIRO, Cláudio. op. cit. p. 173.

${ }^{32}$ Cf. GUERRA, Sidney Cesar Silva; COSTA, Rafaela Rodrigues. O Direito Fundamental à Boa Administração $e \quad a$ Legalidade dos Atos Administrativos Municipais. 2018. p. 11. Disponível em < http://publicacoes.unigranrio.edu.br/index.php/rdugr/article/view/5094 > acesso em dezembro de 2020.

${ }^{33}$ MOREIRA NETO, Diogo de Figueiredo. Curso de direito administrativo: parte introdutória, parte geral e parte especial. 15. ed. Rio de Janeiro: Forense, 2009. p. 119.
} 
Administração Pública e com isso reduzam a própria capacidade do Estado em implementar e concretizar direitos, ao que, evidentemente, devem estar sujeitos a controle.

Em suma, Carvalho afirma que o direito fundamental à boa governança "há de se colocar como um instrumental jurídico que se coaduna com os anseios democráticos e com a ideia de governança, a acarretar à Administração Pública e aos gestores públicos vinculação aos ideais e mandamentos constitucionais" 34 .

Ainda, como uma pá de cal, o muito bem colocado conceito de Juarez Freitas ${ }^{35}$ sobre o direito fundamental à boa governança, no sentido de que ele reflete:

A eficiente e eficaz, proporcional cumpridora de seus deveres, com transparência, sustentabilidade, motivação proporcional, imparcialidade e respeito à moralidade, à participação social e à plena responsabilidade por suas condutas omissivas e comissivas. A tal direito corresponde o dever de observar, nas relações administrativas, a cogência da totalidade dos princípios constitucionais e correspondentes prioridades.

Percebe-se, portanto, a amplitude que a boa governança assume através de uma concepção de verdadeiro direito fundamental.

\section{A função hermenêutica do direito fundamental à boa governança}

Dentro do que se apresentou neste trabalho a respeito do Direito Fundamental à Boa Governança, já começa a ficar claro que a sua função hermenêutica se identifica com a perquirição dos anseios sociais e democráticos, relegando-se ao Estado-Administração e aos próprios agentes públicos a submissão aos princípios e regras constitucionais.

Ainda, tal submissão deve voltar-se ao sentido de preservação das capacidades institucionais, para que o Estado-Administração permaneça capaz dar azo e concretude aos direitos fundamentais de um modo geral; devendo ser assegurada ainda a atuação do Poder Judiciário como órgão de controle externo dos aspectos inerentes ao processo de governança, respeitados certos limites de atuação em nome da harmonia e independência entre os poderes republicanos.

Em larga medida, a existência de um Direito Fundamental à Boa Governança confirma dentro do sistema a noção de republicanismo, pois em última análise tem como norte o bem

\footnotetext{
${ }^{34}$ CARVALHO, Valter Alves. O Direito à boa administração pública como instrumento de hermenêutica constitucional. Rio de Janeiro. 2015.2 Disponível em: <http://www.publicadireito.com.br/artigos/?cod=234a1273487bf7b2>. Acesso em: dezembro de 2020. p. 3.

${ }^{35}$ FREITAS, Juarez. Direito Fundamental à Boa Administração Pública. $3^{\mathrm{a}}$ ed. refundida e aumentada. São Paulo. Ed. Malheiros Editores. 2014.
} 
comum de todos os cidadãos a ser garantido e concretizado pelo Estado-Administração ${ }^{36}$. A Administração deve velar pela coisa pública, sob pena de se tornar escassa e ineficaz, até mesmo do ponto de vista econômico, e com isso incapaz de concretizar direitos (na exata compreensão de que todo direito tem um custo).

Sabe-se que a hermenêutica, longe de ser uma atividade de conteúdo meramente declaratório, como já se defendeu no passado, em verdade se trata de uma atividade constitutiva, na medida em que a norma resulta da atividade hermenêutica e não o inverso, estando ainda o processo interpretativo escoimado na pré-compreensão do intérprete e nas peculiaridades do caso concreto ${ }^{37}$. Mais ainda, com o avanço da hermenêutica constitucional, muito diferenciada em relação à hermenêutica clássica; entre outros motivos; por conta das normas plurissignificativas de que tratam as constituições modernas, sobretudo lastreadas em princípios; passa a ser requisitada uma espécie de interpretação cada vez mais democrática, ampliando-se inclusive o rol dos intérpretes da Constituição, a se abandonar uma sociedade fechada, calcada nos órgãos oficiais, e culminando numa "sociedade aberta" de intérpretes da Constituição ${ }^{38}$. Isso porque quanto mais aberta e plural for uma sociedade, na mesma proporção há de ser aberta e plural a interpretação constitucional para que esta reflita a realidade como ela é.

Nesse contexto, portanto, de republicanismo e pluralidade, de trato da coisa pública e de abertura democrática, é que a Administração Pública passa a ser vista não mais como uma mera estrutura burocrática calcada na consecução dos ditos "interesses" do Estado, mas sim como instrumento de busca da consecução dos direitos fundamentais do cidadão. Não é à toa, aliás, que o próprio conceito de "interesse público primário" passa atualmente a ser entendido como um interesse ligado justamente à consecução dos direitos fundamentais ${ }^{39}$.

Em se tratando de um direito de cunho republicano e democrático, portanto, o direito à boa governança se insere no que afirmava Friedrich $M \ddot{u l l e r}{ }^{40}$, ao constatar que uma democracia não se confundiria com um mero dispositivo de técnicas jurídicas para definir

\footnotetext{
${ }^{36}$ Conferir também: CARVALHO, Valter Alves. op. cit. p. 3.

${ }^{37}$ Conferir em: ÁVILA, Humberto. Teoria dos Princípios: da definição à aplicação dos princípios jurídicos. 4a ed. São Paulo: Malheiros, 2005.

38 Conferir: HÄBERLE, Peter. Hermenêutica Constitucional. A Sociedade dos Intérpretes da Constituição: contribuição para a interpretação pluralista e "procedimental" da Constituição. Tradução de Gilmar Ferreira Mendes. Porto Alegre: Sergio Antonio Fabris Editor, 1997.

${ }^{39}$ Nesse sentido: JUSTEN FILHO, Marçal. Curso de Direito Administrativo. $2^{\text {a }}$ ed., ver. e atual. São Paulo: Saraiva. 2006. p. 36-48.

${ }^{40}$ Conferir: MÜLLER, Friedrich. Que grau de exclusão social ainda pode ser tolerado por um sistema democrático?. Tradução de Peter Naumann. In. Revista da Procuradoria-Geral do Município de Porto Alegre, Edição especial, Porto Alegre, 2000. p. 26.
} 
como textos de normas são postos em vigor, como leis são aprovadas; mas a compreensão do que seja democracia se liga ao tratamento dispensado pelo Estado ao Povo, não como súditos nem como seres subumanos, mas individualmente como membros do povo soberano.

É dizer, o sentido hermenêutico do Direito Fundamental à Boa Governança está relacionado ao atendimento do povo e de seus interesses, ao cabo, em dar azo à concretização do que é necessário para garantir os direitos constitucionais dos cidadãos. Somente com esse escopo é que se o considera de fato um direito republicano.

Ainda, o caráter democrático do direito à boa governança denota que os pontos de vista da análise daquilo que deve ser "bom" ou não são múltiplos e plurais, assim como a sociedade moderna e seus valores também o são. Pois não há como falar em democracia quando os escopos do Estado não se coadunam com a multiplicidade e pluralidade do substrato social.

Neste ponto é fundamental a análise do Poder Judiciário como poder responsável pelo controle das políticas públicas, sobretudo num sistema de "Judicial Review”. A boa governança como direito fundamental deve funcionar como importante instrumento para este controle no seu aspecto hermenêutico.

$\mathrm{Na}$ medida em que o reconhecimento do Direito Fundamental à Boa Governança engendra a perspectiva de que a função administrativa é das mais relevantes para a concretização dos direitos fundamentais e que corresponde a uma verdadeira ampliação do espectro de proteção desses direitos, especificamente no aspecto dinâmico relacionado aos processos internos levados a efeito pelo Estado-Administração; tudo está sujeito a controle porque o próprio processo em si é um direito fundamental. O processo há de ser eficaz e eficiente e deve ele representar o que se tem por boa governança, inclusive, sem se desgarrar da eficiência econômica.

Assim sendo, no campo da hermenêutica, o Direito Fundamental à Boa Governança reflete no "Judicial Review" um sentido verdadeiramente proativo, em se impor ao EstadoAdministração a realização de políticas públicas que venham a dar concretude aos direitos fundamentais ou ao menos voltadas para este objetivo; bem assim, por meio de procedimentos que sejam os mais eficazes possíveis e de menor custo possível ao Erário, incluindo-se, assim, na análise hermenêutica também o critério econômico das políticas públicas.

Cabe frisar que, dentro deste aspecto, está incluída também a possível responsabilização do agente público quando venha a se distanciar tanto da finalidade nos direitos fundamentais de um modo geral, não dando azo a sua consecução, ou caso também se distancie do próprio Direito Fundamental à Boa Governança, quando estará em última análise mal versando com o dinheiro público. 
É de se questionar, contudo, se esta possibilidade de o Judiciário analisar a título de controle os aspectos finalísticos do ato administrativo, tendo em conta ainda o aspecto econômico, não cria uma demasiada possibilidade de ingerência indevida do Judiciário em face da Administração, de certo modo a se autorizar uma crescente hipertrofia de um Poder perante outro.

É nesse campo que residem muitas críticas ao que se costuma chamar de "ativismo judicial”, em expressão absolutamente detrimentosa da atuação do Judiciário no controle de políticas públicas ${ }^{41}$.

É claro que a questão é importante, pois não se deseja uma hipertrofia do Poder Judiciário, antes apenas que este cumpra suas funções de guardião dos direitos fundamentais. Por isso é que se considera inexistir hipertrofia de um Poder quando este dá azo ao que está na Constituição e que, em última análise, representa a vontade do povo, a qual está acima de todos os Poderes.

Além disso o controle de constitucionalidade a cargo do Poder Judiciário é absolutamente necessário e deve prevalecer, dada a necessidade de "preservação das condições essenciais de funcionamento do Estado de Direito Democrático", que também corresponde a um valor supremo da Constituição ${ }^{42}$.

Não por outra razão, e sem deixar de lado o risco de um ativismo judicial indevido, é que se reconhece também no Direito Fundamental à Boa Governança um sentido hermenêutico de autocontenção, na medida em que não deve de fato o Judiciário se arvorar na função de administrador, pois a governança pressupõe, como visto, a ideia de democracia. E de fato não há democracia na hipertrofia de um Poder perante outro, mas sim no diálogo entre eles e no reconhecimento das capacidades institucionais de cada um desses Poderes.

Portanto, a função hermenêutica do Direito Fundamental à Boa Governança centra-se dentro de um binômio, cujos extremos podem ser assim representados: de uma lado, a imposição ao administrador das finalidades calcadas na consecução dos direitos fundamentais, reconhecidos como conteúdo do verdadeiro interesse público primário, e ainda, sob procedimentos que atendam a eficiência inclusive no campo econômico; de outro lado, a

\footnotetext{
${ }^{41}$ Costuma-se, inclusive, classificar as teorias sobre o tema do ativismo judicial em: a) Procedimentalista, identificada com a ideia de que a jurisdição constitucional deve apenas se ater à proteção dos pressupostos ncessários ao bom funcionamento da democracia, portanto mais inclinada à ideia de contenção judicial; e b) Substancialista, mais alinhada com o sentido de que a jurisdição constitucional deve abarcar os valores substantivos da Constituição, portanto, mais condizende com um atuação proativa do Judiciário. Nesse sentido: SARMENTO, Daniel. O Neoconstitucionalismo no Brasil: riscos e possibilidades. Revista Brasileira de Estudos Constitucionais, n. 9, 2009. p. 95-131.

${ }^{42}$ Sobre o tema: BARROSO, Luiz Roberto. op. cit. p. 386.
} 
autocontenção para os casos em que se identifique que a atuação do Judiciário irá se imiscuir indevidamente na atividade própria do Estado-Administração, adentrando-se de forma imprópria no mérito dos atos administrativos em geral.

Se escorada nos limites deste binômio estiver a compreensão hermenêutica do Direito Fundamental à Boa Governança ou Direito Fundamental à Boa Administração, pode-se dizer que estar-se-á atendendo aos aspectos democrático e republicano de que se sustenta o direito, atendendo-se a contento a perquirição dos direitos fundamentais consagrados na Constituição e sem macular o princípio da harmonia e independência entre os Poderes da República.

Por fim, poder-se-ia questionar se a autocontenção por parte do Poder Judiciário é mesmo possível e se não haveria campo para abusos, desfazendo-se por completo o argumento da limitação harmônica e democrática do Estado-Juiz em face do seu controle perante o Estado-Administração, a fim de evitar ativismos indesejáveis. Isto é, quem imporá limites ao Judiciário senão ele mesmo?

E a resposta não pode ser diferente, é ele mesmo, o Judiciário, daí o nome de autocontenção, pois não se pode esquecer que o Judiciário não é apenas um ente unitário, mas sim um grande sistema em que debatem pela via do argumento vários atores, advogados, membros do Ministério Público e até amigos da Corte, para a dialógica formação de uma decisão judicial. Assim deve ser, aliás, pelo aspecto plural de que se cerca a interpretação constitucional nos dias de hoje, como já abordamos em Peter Häberle ${ }^{43}$.

Mais ainda, não se pode olvidar de que o Judiciário é uma estrutura escalonada em que ocorre sempre a revisão das decisões judiciais, via recurso ou meios de impugnação ou até reexames necessários ou recursos de ofício, o que constitui um verdadeiro mecanismos de controle de tribunais perante juízes e de tribunais superiores perante tribunais locais, além de, por fim, com a última palavra sobre a Constituição, o socorro à Corte Constitucional.

Portanto, a autocontenção é sim um limite possível e viável, havendo de se concretizar como um dos lados do dito binômio da interpretação do Direito Fundamental à Boa Governança, ombreado, como dissemos, pelo controle proativo finalístico e procedimental das políticas públicas por parte do Poder Judiciário.

\footnotetext{
${ }^{43}$ HÄBERLE, Peter. Hermenêutica Constitucional. A Sociedade dos Intérpretes da Constituição: contribuição para a interpretação pluralista e "procedimental" da Constituição. Tradução de Gilmar Ferreira Mendes. Porto Alegre: Sergio Antonio Fabris Editor, 1997. p. 30.
} 


\section{CONCLUSÕES}

Não há dúvida de que o complexo processo hermenêutico constitucional é elemento fundamental para a necessária interpenetração entre normatividade e realidade conforme aduz, inclusive, Konrad Hesse ${ }^{44}$. Daí porque a importância do estudo do sentido hermenêutico do Direito Fundamental à Boa Governança.

Identificado o Direito Fundamental à Boa Governança sob os aspectos procedimental, econômico e finalístico, é possível enquadrá-lo, de forma expressa consoante ocorre na Europa ou implícita, no caso brasileiro, dentro do sistema como um elemento de importância capital; um verdadeiro vetor, para a busca da concretização dos direitos fundamentais em geral, em destaque para direitos sociais, eis que a sua existência promove um fecundo diálogo institucional entre os Poderes.

O reconhecimento desse fundamental direito eleva a atividade administrativa e o Estado-Administração a um patamar mais alto dentro da função de concretizar o interesse público primário, identificado este como um interesse finalístico calcado propriamente nos direitos fundamentais. Mais ainda, coloca o Poder Judiciário como traço essencial do controle da atividade administrativa; seja no sentido de impor à Administração o atendimento ou ao menos o direcionamento ao atendimento dos direitos fundamentais do cidadão ou quanto à imposição de escolhas administrativas e de processos legalmente e economicamente viáveis; com o fulcro na salvaguarda da coisa pública, e com isso, na manutenção do Estado como ente capaz de dar efetiva concretização aos direitos e livre da escassez de recursos que o tornaria inócuo e inepto para tal mister.

Ainda, sem deixar de se atentar para o risco de um indevido ativismo judicial, reconhecer no Direito Fundamental à Boa Administração o elemento necessário de autocontenção do Estado-Juiz quando a sua interferência tender a meramente se imiscuir na atividade própria do Estado-Administração; sobretudo, quando não identificada na possível e eventual atuação positiva do Poder Judiciário uma ostensiva imposição de caminhos constitucionalmente consagrados pelos direitos fundamentais ou ao menos um equívoco de procedimento no agir administrativo, ainda que do ponto de vista econômico.

Por fim, além de producente mostra-se bastante válida a introdução de limites ao sentido hermenêutico do Direito Fundamental à Boa Governança. Limites estes que podem

\footnotetext{
${ }^{44}$ Cf. HESSE, Konrad. Elementos de Direito Constitucional da República Federal da Alemanha. Porto Alegre: Sergio Antonio Fabris Editor, 1998.
} 
ser identificados no binômio: controle proativo finalístico e procedimental x autocontenção em matéria de puro mérito administrativo.

Assim, uma vez respeitado o binômio dos limites propostos e observado o próprio sentido do controle judicial das políticas públicas sob o prisma do Direito Fundamental à Boa Governança, atendidos estarão os aspectos democrático e republicano a que serve o direito. Com isso, não haverá o malfadado ativismo judicial ou qualquer hipertrofia indevida de um Poder republicano sobre outro.

\section{REFERÊNCIAS}

ÁVILA, Humberto. Teoria dos Princípios: da definição à aplicação dos princípios jurídicos. 4a ed. São Paulo: Malheiros, 2005.

BARROSO, Luís Roberto. Curso de Direito Constitucional Contemporâneo: os conceitos fundamentais e a construção do novo modelo. São Paulo: Saraiva, $1^{\mathrm{a}}$ Ed., 2009.

CARVALHO, Valter Alves. O Direito à boa administração pública como instrumento de hermenêutica constitucional. Rio de Janeiro. 2015.

CARVAlHO, Valter Alves. O Direito à Boa Administração Pública: Uma Análise no Contexto dos Direitos de Cidadania no Brasil. Dissertação de Mestrado. Universidade Federal Fluminense. 2013.

COELHO, Claudio Carneiro B. P. Teoria do Pêndulo Econômico-hermenêutico. Uma releitura da relação entre Estado, Direito e sociedade em tempo de (pós) crise. Rio de Janeiro: University Institute. 2021. P. 110

. Ainda é Possível Falar em Direito Sociais? In. Os Desafios do Direito no Século XXI: Violência, Criminalização, Consenso, Tutela Digital e Laboral. Coord. Manuel Monteiro Guedes Valente. Coimbra: Almedina. 2019.

CÓDIGO EUROPEU DE BOA CONDUTA ADMINISTRATIVA. Provedor de Justiça Europeu. 2002.

COMISSÃO DAS COMUIDADES EUROPEIAS. Governança Europeia: Um Livro Branco. 2001.

FREITAS, Juarez. Direito Fundamental à Boa Administração Pública. $3^{a}$ ed. refundida e aumentada. São Paulo. Ed. Malheiros Editores. 2014.

GUERRA, Sidney Cesar Silva; COSTA, Rafaela Rodrigues. O Direito Fundamental à Boa Administração e a Legalidade dos Atos Administrativos Municipais. 2018.

HÄBERLE, Peter. Hermenêutica Constitucional. A Sociedade dos Intérpretes da Constituição: contribuição para a interpretação pluralista e "procedimental" da Constituição. Tradução de Gilmar Ferreira Mendes. Porto Alegre: Sergio Antonio Fabris Editor, 1997.

HART, Herbert Lionel Adolphus. O conceito de direito. São Paulo: Martins Fontes, 2012.

HESSE, Konrad. Elementos de Direito Constitucional da República Federal da Alemanha. Porto Alegre: Sergio Antonio Fabris Editor, 1998. 
HOLMES, Stephen; SUSTEIN, Cass R. O Custo dos Direitos: Por que a Liberdade Depende de Impostos. Tradução de Marcelo Brandão Cipolla. São Paulo: Editora WMF Martins Fontes, 2019.

JUSTEN FILHO, Marçal. Curso de Direito Administrativo. $2^{\text {a }}$ ed., ver. e atual. São Paulo: Saraiva, 2006.

KAUFFMANN, Daniel. Replanteando Gobernabilidad. Las Lecciones Empíricas Desafían a los Convencionalismos. Instituto del Banco Mundial. 2010.

LASSALE, Ferdinand. O que é uma Constituição. Rio de Janeiro: Larmert, 1960.

LIRA, Bruno de Oliveira. O Direito Fundamental à Boa Administração sob a ótica do Estado. 2011.

MELLO, Celso Antônio Bandeira de. Discricionariedade e controle jurisdicional. $2^{\mathrm{a}}$ ed. $8^{\mathrm{a}}$ tiragem. São Paulo: Malheiros, 2007.

MOREIRA NETO, Diogo de Figueiredo. Curso de direito administrativo: parte introdutória, parte geral e parte especial. 15. ed. Rio de Janeiro: Forense, 2009.

MÜLLER, Friedrich. Que grau de exclusão social ainda pode ser tolerado por um sistema democrático?. Tradução de Peter Naumann. In. Revista da Procuradoria-Geral do Município de Porto Alegre, Edição especial, Porto Alegre, 2000.

PRATS, Joan Oriol. El concepto y el análises de la gobernabilidad. Revista Instituciones y desarrollo. Institut Internacional de Governabilitat de Catalunya, N 14-15. 2003.

REIS, Fábio Wanderley. Governabilidade, instituições e partidos. Novos Estudos CEBRAP, $n^{\circ} 41$, março/1995.

ROCHA, J. A. Oliveira. Gestão pública e modernização administrativa. INA Editora, 2014.

SARMENTO, Daniel. O Neoconstitucionalismo no Brasil: riscos e possibilidades. Revista Brasileira de Estudos Constitucionais, n. 9, 2009.

SOUVIRÓN MORENILLA, José Maria. Sentido y alcance del derecho a una buena administración. In: RODRÍGUEZ, Carmen María Ávila. RODRÍGUEZ, Francisco Gutiérrez (Coord.). El derecho a una buena administración y la ética pública. Valencia: Tirant lo Blanch, 2011.

THE WORLD BANK. Strengthening World Bank Group engagement on governance And anticorruption, 2007.

VALLE, Vanice Regina Lírio do. Direito Fundamental à boa administração e governança: democratizando a funcao administrativa. Tese de Pós-doutorado apresentado na Fundação Getúlio Vargas. Rio de Janeiro 2010. 